\title{
Avaliação no Ensino Médio Politécnico como processo de construção de saber na relação professor-aluno
}

\author{
Evaluation in the Polytechnic High School how process know \\ construction in the student-teacher relationship
}

\author{
Everton BEDIN ${ }^{1}$ \\ José Claudio DEL PINO²
}

\begin{abstract}
Resumo
Este artigo tem por objetivo apresentar as concepçóes docentes e discentes sobre as atividades avaliativas no Ensino Médio Politécnico, credenciando as contribuiçôes dessa nova metodologia avaliativa na formaçáo do sujeito crítico, reflexivo e autônomo, por meio da construção de saberes na relação professor-aluno. Fundamenta-se em dados de pesquisa coletados por meio de interaçóes nas redes sociais e questionário estruturado com estudantes e professores do último ano do ensino médio. A análise ocorreu de forma qualiquantitativa, utilizando softwares, tabelas e interpretaçóes que permitiram identificar os aspectos construtivistas na metodologia de avaliação para a qualificaçáo dos processos de ensino e aprendizagem.
\end{abstract}

Palavras-chave: Avaliação. Ensino Médio Politécnico. Relação professor-aluno.
Abstract

This Article aims present conceptions the teachers and students on evaluation activities in the Polytechnic High School, accrediting contributions this new evaluative methodology the formation of the critical subject, reflective and autonomous, through the construction of knowledge the teacher-student relationship. It is based on survey data collected through interactions in social networks and structured questionnaire with the students and teachers last year of high school. The analysis occurred both qualitatively and quantitatively, using software, tables and interpretations that have identified constructivists aspects in assessment methodology for qualification of teaching and learning processes, as well as their effects in the relationship between teachers, students and knowledge.

Keywords: Evaluation. Polytechnic High School. Teacher-student relationship.

1 Doutor em Educação em Ciências: química da vida e saúde. Professor Adjunto da Universidade Luterana do Brasil, campus Canoas. Universidade Luterana do Brasil, ULBRA, Avenida Farroupilha, 8001, bairro: São José, Canoas-RS, CEP: 92425-900. E-mail: <bedin.everton@gmail.com>.

2 Doutor em Engenharia de Biomassa. Professor Associado da Universidade Federal do Rio Grande do Sul. PPG Educação em Ciências: Química da Vida e Saúde, Universidade Federal do Rio Grande do Sul, UFRGS, Rua Ramiro Barcelos, 2600 - Prédio Anexo, Porto Alegre-RS, CEP: 90035-003. E-mail: <delpinojc@yahoo.com.br>.

R. Educ. Públ.

Cuiabá

v. 27

n. 66

p. $975-996$

set./dez. 2018 


\section{Introdução}

O estado do Rio Grande do Sul, nos últimos três anos, vem sofrendo mudanças na esfera educacional, uma vez que a proposta curricular enviada pela Secretaria de Educação do supracitado estado, no ano de 2011, remetia à ideia e à concepção de democratização e garantia de saberes e conhecimentos a todos, assegurando uma educação de acesso e qualidade. Apontavam as escrituras do documento a permanente instrumentalizaçáo dos educandos quanto à compreensão do significado da ciência, das letras e das artes; do processo histórico de transformação da sociedade e da cultura; da língua portuguesa como instrumento de comunicação e acesso ao conhecimento; e do exercício da cidadania (SEDUC, 2011, p. 3).

$\mathrm{Na}$ múltipla teia de reestruturação, houve mudanças, além de o currículo escolar considerar o conhecimento por área e não mais por disciplinas e as práticas pedagógicas estarem vinculadas à necessidade de atividades colaborativas e de cunho interdisciplinar na organização pedagógica quanto ao ato de avaliar o conhecimento construído e adquirido pelos educandos.

Dessa forma, considera-se pertinente investigar, por meio das concepções discentes e docentes, como os trabalhos avaliativos (provas, seminários, apresentaçóes, memórias, relatórios), emergentes com a reestruturação do Ensino Médio em Ensino Médio Politécnico, buscam apontar a padronizaçáo das atividades docentes para a relação professor-aluno, credenciando as contribuiçóes dessa nova metodologia avaliativa na formaçáo do sujeito crítico, reflexivo e autônomo.

Nessa perspectiva, entende-se que a reestruturação no ensino médio gaúcho trouxe a necessidade de a avaliaçáo ser desenvolvida em um caráter emancipatório, a qual, na visão de Saul (1995, p. 61), tem dois princípios básicos: "[...] iluminar o caminho da transformação e beneficiar as audiências, no sentido de torná-las autodeterminadas." Em outras palavras, a avaliação praticada na escola deve estar centrada e comprometida com o futuro do educando, constituindo-se em açóes que, a partir do autoconhecimento crítico, auxiliam naquilo que se pretende transformar. Além do mais, essa avaliação está diretamente ligada ao professor, permitindo a ele, "[...] através da consciência crítica, que imprima uma direção às suas açóes nos contextos em que se situa, de acordo com valores que elege e com os quais se compromete no decurso de sua historicidade." (SAUL, 2015, p. 1309).

Nesse desenho, Saul (2015, p. 1309) expóe que a avaliação emancipatória tem como principais características manter: 
1. compromisso com a educação democrática, objetivando práticas de inclusão e desenvolvimento de educandos autônomos; 2. valorizaçáo do educando como sujeito do seu processo de aprendizagem; 3. priorizaçáo dos aspectos qualitativos do desenvolvimento do educando; 4 . proposta de relação pedagógica democrática e horizontal entre educador e educando; 5 . valorizaçáo do processo e os resultados do ato de ensinar-aprender; 6. utilizaçáo de processos dialógicos e participativos; e 7 . objetivo de melhorar o processo ensino-aprendizagem e de replanejar a ação educativa.

Portanto, ao entender as ideias de Saul sobre a avaliação emancipatória, pode-se apreender que a reestruturação do perfil avaliativo no ensino médio gaúcho requer que o processo seja desenvolvido em caráter mediador e formativo, conectado aos processos de ensino e aprendizagem, não sendo resumido a testes e provas. Evidentemente, acredita-se que eles são importantes no processo de avaliação, contudo, cabe ao professor analisar os resultados de forma avaliativa e não examinadora, como defende Luckesi (2003, p. 2011). Para o autor, o ato de avaliar consiste no diagnóstico e na reorientação do aluno, averiguando os pontos positivos para reforçá-los e os pontos negativos para melhorá-los.

Nesta perspectiva, considerando a concepçáo de Hoffmann (2003) sobre a avaliação, a qual a determina como uma mediação para o diálogo e a interação, em que o conhecimento se propaga em um mesmo tempo e cenário por professores e alunos, o presente artigo tem por objetivo apresentar as concepçóes docentes e discentes sobre as atividades avaliativas de cunho emancipatório no Ensino Médio Politécnico desenvolvidas em uma escola pública no norte do estado gaúcho, credenciando as contribuiçóes dessa nova metodologia avaliativa na formação do sujeito crítico, reflexivo e autônomo, por meio da construção de saberes na relação professor-aluno.

Diante dos fatos e ponderando a avaliação como processo e ação que fortalece a construção do sujeito por meio de transformações e mudanças, uma vez que deve assumir caráter educativo, viabilizando ao estudante apropriar-se do seu processo de aprendizagem e, ao professor e à escola a análise aprofundada do processo dos alunos, oportunizando replanejamento e reorientação de atividades em outros espaços e tempos (SEDUC, 2011, p. 10), é contingente destacar que a função da avaliação num contexto de formação está relacionada aos objetivos da escola; assim, é necessário que o processo avaliativo favoreça a construção de uma postura pedagógica emancipatória e dialógica e considerar as diferenças e particularidades de cada um. 
Nesse aspecto, a avaliação emancipatória assume função formativa, proporcionando integração professor-aluno na formação individualizada, a fim de articular as características da escola com os objetivos dos professores e estudantes, garantindo a inserção democrática dos aportes teóricos do projeto político-pedagógico, pois, segundo Luckesi (1984, p. 9), “[...] a avaliação é um julgamento de valor sobre manifestaçóes relevantes da realidade, tendo em vista uma tomada de decisão."

No artigo, em sua sequência, apresenta-se o desenho da pesquisa, parte que proporciona conhecimento sobre o público-alvo, enfatizando sua localidade e realidade; na sequência, define-se a proposta da pesquisa e os processos utilizados para coletar os dados. Posteriormente, apresenta-se a seção de Resultados e discussóes, parte integrante que, por meio de tabelas, gráficos, grafos e imagens, expóe-se os dados coletados, ligeiramente qualificados com aporte teórico. $\mathrm{Na}$ última parte, apresentam-se as Conclusóes, enfatizando o objetivo, as certezas e incertezas sobre o processo avaliativo, além de reavaliar o seu desenvolvimento. No final, como base e aspecto para leituras mais profundas, disponibilizam-se as Referências bibliográficas utilizadas para a confecção deste artigo.

\section{Desenho da pesquisa}

Realizou-se uma pesquisa de caráter exploratório e objetivo do tipo levantamento de estudo de caso, com profissionais da educação e estudantes envolvidos nos processos de ensino e aprendizagem que desempenhassem suas atividades em duas turmas do $3^{\circ}$ ano do Ensino Médio Politécnico, em uma escola pública do norte do Estado do Rio Grande do Sul, especificamente em Ibiraiaras ${ }^{3}$.

Quanto ao estudo de caso, Yin (1994, p. 13, tradução nossa) define-o com base nas "[...] características do fenômeno em estudo e com apoio num conjunto de características associadas ao processo de recolha de dados e às estratégias de análise dos mesmos." Ou seja, trata-se de uma abordagem metodológica de investigação especialmente adequada quando se procura compreender, explorar e descrever fatos e contextos complexos, nos quais estão simultaneamente envolvidos diversos fatores.

3 Ibiraiaras, município do estado gaúcho, está localizada a aproximadamente 240 quilômetros da capital Porto Alegre-RS. Possui cerca de 8.000 habitantes e destaca-se na regiáo por possuir apenas uma escola estadual, a qual conta com a participaçáo efetiva e ativa de toda a comunidade local. 
A investigação considerou como universo os profissionais atuantes nas turmas supracitadas das quatro áreas do conhecimento, não a totalidade dos professores da escola. Essa atividade ocorreu em dois tempos: 1- momento: forma virtual nas redes sociais, sendo incluídos 42 estudantes e oito professores; e 2- momento: forma presencial em sala de aula por meio de um questionário estruturado aos estudantes. Em ambas as formas de coleta de dados, instigavam-se os sujeitos sobre os conhecimentos, concepçóes e perspectivas em relação à avaliação que estava sendo desenvolvida na escola.

Os resultados apresentados, tanto virtual quanto presencialmente, foram analisados de forma qualiquantitativa. Diante das interaçôes na rede, optouse por analisá-las por meio da Teoria de Grafo, entendendo a relação entre os sujeitos pelo software Ucinet ${ }^{4}$, na interpretação das escrituras, abstraindo as palavras mais destacadas com auxílio do software Wordle 5 . Já para o questionário, parte presencial, apenas para os estudantes, os resultados, demonstrados em percentuais simples, foram analisados de forma comparativa entre os dois gêneros da pesquisa. Para o levantamento, agruparam-se os dados em planilha (software Microsoft Excel), permitindo sua classificação de acordo com o total de respostas obtidas, independentemente das turmas. Assim, os gráficos, tabelas e imagens preencheram o corpo deste trabalho.

Ressalva-se que a pesquisa não trouxe problemas aos participantes, visto que foram necessários alguns minutos para a realização da coleta dos dados presencialmente, garantindo-se o anonimato dos sujeitos. Nas duas fases, presencial e virtual, houve aprovação no Comitê de Ética na Pesquisa, tendo-se em vista o desenvolvimento de uma pesquisa com estudantes e professores, o sigilo de cada um e a aprovação para participação. Do mesmo modo, destaca-se que os sujeitos desta investigação não receberam benefício direto ao participarem da presente pesquisa, entretanto, puderam obter conhecimento, por meio das interações a respeito da concepção do colega sobre a avaliação.

4 UCINET: é um dos aplicativos mais abrangentes para a análise de redes sociais e aproximação de dados, pois contém um grande número de rotinas analíticas para a rede (BORGATTI et al., 2002). Link para download: <https://sites.google.com/site/ucinetsoftware/downloads $>$.

5 Link disponível para realizar Nuvem de Palavras com o software Wordle: <http://www.wordle.net/create>. 


\section{Resultados e discussões}

Para alcançar o objetivo da presente pesquisa, organizou-se um grupo fechado, a fim de se coletar os dados no segundo semestre de 2014, no facebook, considerada uma das maiores redes online em comunidades virtuais, para analisar o diálogo correspondente à questão de avaliação no Ensino Médio Politécnico entre os professores e alunos do terceiro ano. Para melhor satisfação e entendimento sobre as escrituras, aplicou-se um questionário aos estudantes. Tal questionário era de cunho qualitativo, apresentando questóes fechadas. Ressalva-se que no início das atividades os participantes foram informados acerca do sigilo dos dados e dos aspectos éticos do estudo.

Sobre o questionário, avultar-se que havia uma questáo central e, dessa, cinco ramificaçóes, as quais os estudantes deveriam apontar, dentro de uma escala de concordância, se haviam sido alcançadas ou não no desenvolvimento das atividades. A escala de concordância variava em Muito Bom, Bom, Regular e Fraco. As ramificações, considerando as indicações dos estudantes, se apresentam nos gráficos seguintes. Observe o quadro 1, na sequência, para entender melhor a questão disponibilizada.

\section{Quadro 1 - Questão apresentando as ramificações e a escala de concordância presente no questionário}

\begin{tabular}{|c|c|c|c|c|c|}
\hline \multirow{6}{*}{$\begin{array}{c}\text { Em relação a } \\
\text { avaliação, } \\
\text { acredita-se que foi: }\end{array}$} & & $\begin{array}{l}\text { Muito } \\
\text { Bom }\end{array}$ & Bom & Regular & Fraco \\
\hline & Desenvolvida com coerência & & & & \\
\hline & $\begin{array}{l}\text { Relacionada com as } \\
\text { atividades }\end{array}$ & & & & \\
\hline & Divulgada com antecedência & & & & \\
\hline & Reforço à aprendizagem & & & & \\
\hline & $\begin{array}{l}\text { Apresentada de múltiplos } \\
\text { métodos e técnicas }\end{array}$ & & & & \\
\hline
\end{tabular}

Fonte: Os autores (2015).

Ressalta-se que a análise dos questionários foi realizada individualmente, mas que, para maior compreensáo dos dados, apresentam-se os gráficos nas individualizaçóes das ramificaçôes, contemplando os apontamentos dos meninos e das meninas, isso é, optou-se por apresentar os gráficos por diferença de gênero, apontando a semelhança entre as respostas e a significância do caráter da avaliaçáo 
emancipatória tanto para os meninos quanto para as meninas; logo, a avaliação emancipatória tem efeitos significativos para os dois gêneros dos sujeitos.

Nesse sentido, apesar de se apresentar os gráficos por diferença de gênero, é cogente e importante afirmar que em nenhum momento foram priorizadas ou minimizadas as concepçóes e consideraçóes dos diferentes sujeitos e que também não se buscou comparar as respostas ou traçar um perfil de escolha entre os sujeitos. Pelo contrário, a análise dos dados foi realizada por diferença de gênero para mostrar que a mudança no caráter da avaliação docente surtiu efeito expressivo em ambos os gêneros, pois parte-se do pressuposto de que uma análise geral, apresentando resultados conjuntos, não demonstraria, exatamente, como o estilo emancipatório da avaliação docente afetou os segmentos escolares como um todo.

O primeiro gráfico apresentado, gráfico 1 , diz respeito à ramificação Avaliação desenvolvida com coerência. Analisando-o, pode-se perceber que a maioria dos sujeitos, de ambos os gêneros, concorda em uma escala de Bom; logo, acreditase que as atividades avaliativas estavam entrelaçadas aos processos de ensino e aprendizagem de forma satisfatória, já que os estudantes as perceberam com coerência e eficiência.

\section{Gráfico 1: Resultado da análise sobre a $1^{\mathrm{a}}$ ramificação disponibilizada no questionário}

\section{Avaliação desenvolvida com coerência}

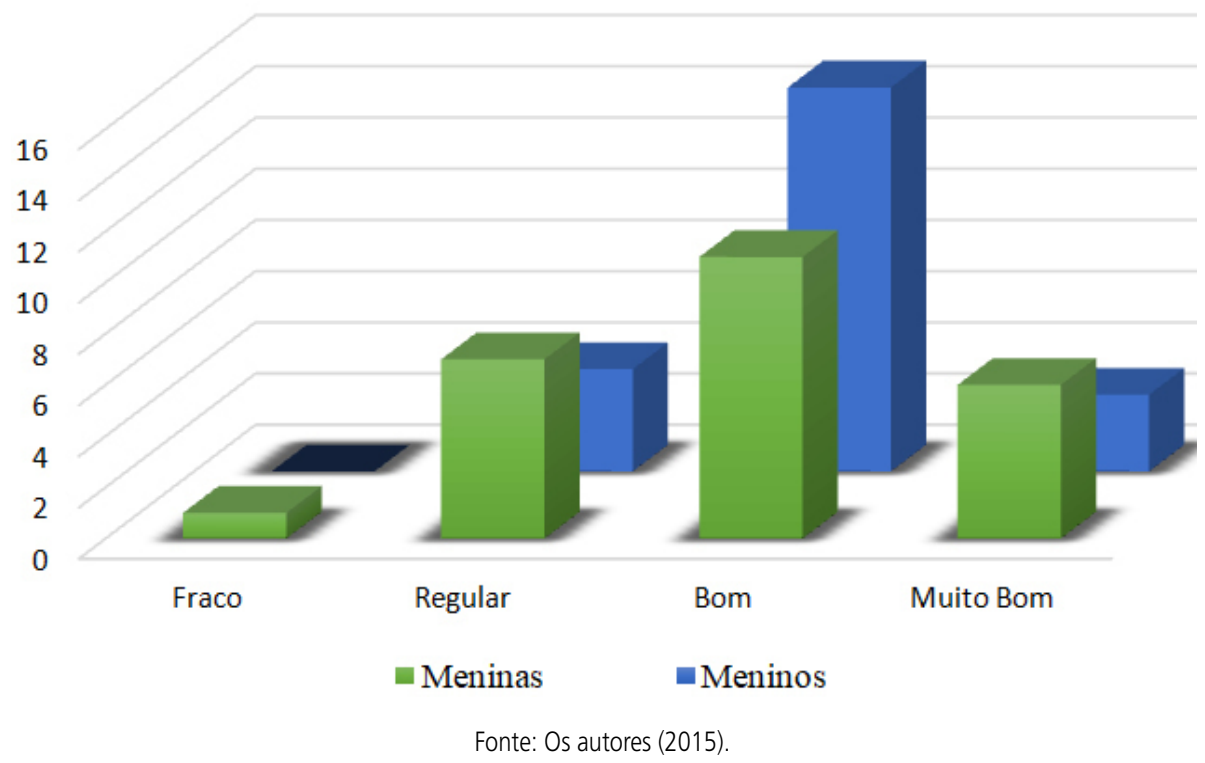


Nesse desenho, entende-se a finalidade da avaliação para os processos de ensino e aprendizagem, pois auxilia na criação de condiçóes para o desenvolvimento de competências e habilidades nos estudantes. Assim, o estudante prepara-se para ler e interpretar textos de revistas, jornais e manuais, demonstrando que possui recursos para a abordagem de situaçóes complexas, identificação de códigos e símbolos, interpretando coerentemente, mesmo que náo tenha nenhum contato com os autores dos textos. Portanto, quanto mais completa for a formulação das questóes, melhor será a formação do aluno para sua vida profissional (MORETO, 2008, p. 90)

De acordo com Caldeira (2000):

A avaliação escolar é um meio e não um fim em si mesma; está delimitada por uma determinada teoria e por uma determinada prática pedagógica. Ela não ocorre num vazio conceitual, mas está dimensionada por um modelo teórico de sociedade, de homem, de educação e, consequentemente, de ensino e de aprendizagem, expresso na teoria e na prática pedagógica. (p. 122).

Assim, percebe-se a necessidade de o professor desenvolver atividades avaliativas de forma coerente com o apresentado em sala de aula, pois esses mecanismos são essenciais para a construção do sujeito crítico e reflexivo, uma vez que devem partir, necessariamente, do contexto sociocultural do aluno.

O segundo gráfico, gráfico 2, representando a ramificação Avaliação relacionada com as atividades, assim como o gráfico anterior, teve uma alta concordância, em ambos os gêneros, de Bom. De tal modo, considera-se que as avaliaçóes, de certa forma, buscaram sempre enfatizar as atividades trabalhadas dentro da sala de aula, garantindo melhor compreensão e entendimento dos estudantes. 
Gráfico 2: Resultado da análise sobre a $2^{\mathrm{a}}$ ramificação disponibilizada no questionário

Avaliação relacionada com as atividades

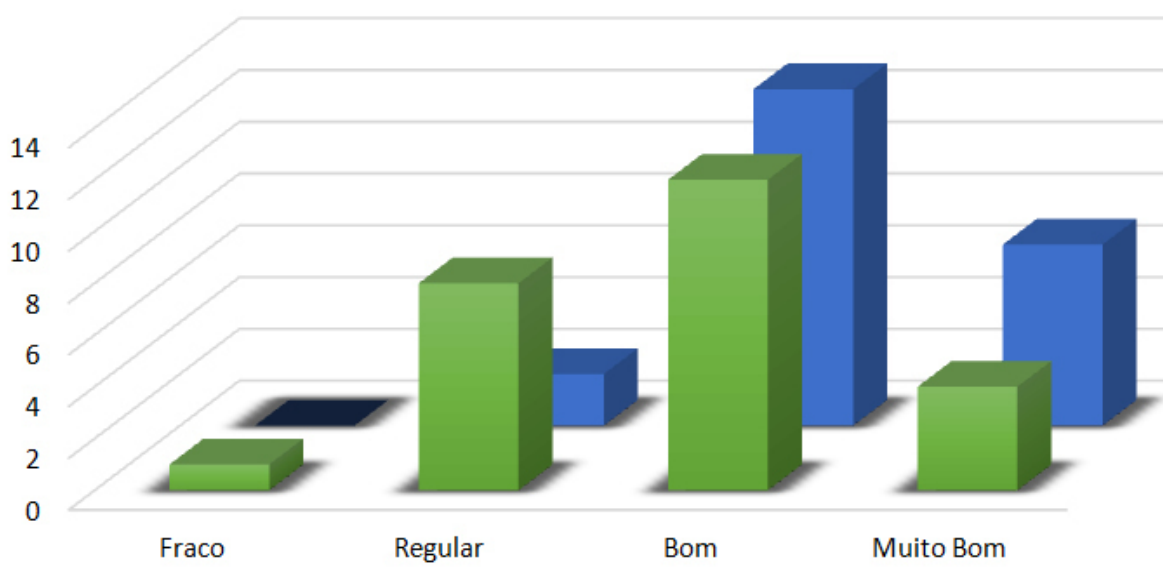

- Meninas - Meninos

Fonte: Os autores (2015).

Portanto, destaca-se que quando a avaliação está na direção das atividades desenvolvidas, indiferentemente do contexto, o estudante deixa de ser um simples repetidor de informaçóes, passando a ser construtor da própria aprendizagem, usufruindo das informaçóes para compreender e dar significado ao contexto. Da mesma forma, entende-se que cabe, também, ao estudante o papel de escolher o que deve ou não saber, interferindo na maneira pela qual essa aprendizagem deva ser feita, afinal ele deve buscar aprender o que traz significados, de forma planejada e sistematizada, na relação entre professor-aluno.

Nesse viés, a nova concepção referida entrelaça uma relação significativa entre professor, estudante e conhecimento, aconselhando-se em uma perspectiva construtivista-sociointeracionista, representada pela característica fundamental de interação que se estabelece entre professor, aluno e conhecimento (MORETO, 2008, p. 101). Portanto, passa a ser elemento mediador (catalisador) da aprendizagem do estudante, favorecendo a interação entre o aluno e o conhecimento socialmente construído, pois, segundo Freire (1996), "ensinar não é transferir conhecimento, mas criar as possibilidades para sua própria produção ou sua construção." (p. 47).

Nesse mesmo desenho, Álvarez Méndez (2002, p. 29) reflete que “[...] o conhecimento deve ser o referente teórico que dá sentido global ao processo 
de realizar uma avaliação, podendo diferir segundo a percepção teórica que guia a avaliação. Aqui está o sentido e o significado da avaliação e, como substrato, o da educação."

Assim, o ensino deixa de ser uma transmissão de conhecimentos (verdades prontas), para constituir-se em um processo de elaboração de situaçóes de problemas e questionamentos didático-pedagógicos que promovam a qualificaçáo dos processos de ensino e aprendizagem, favorecendo a construção de relaçóes significativas entre componentes de um universo simbólico (MORALES, 2003, p. 103).

No terceiro gráfico, gráfico 3, o qual reflete sobre a questão da divulgação das avaliaçóes, pode-se perceber que os estudantes contemplam a concordância Muito Bom, afirmando que os professores divulgavam com antecedência as avaliaçóes previstas e normatizadas. Entende-se ser necessária a divulgaçáo prévia de qualquer atividade avaliativa, pois o estudante tem um papel ativo no processo da resoluçáo dos problemas para a qualificação da própria aprendizagem, podendo o professor ajudar de forma coerente e racional, isso é, planejar sua intervenção pedagógica visando facilitar a aprendizagem, uma vez que, segundo Moreto, (2008), “[...] esse planejamento leva em conta quatro fatores principais: suas qualidades pessoais, as características de seus alunos, as especificidades da disciplina que leciona e os recursos disponíveis na escola." (p. 68).

Gráfico 3: Resultado da análise sobre a $3^{\mathrm{a}}$ ramificação disponibilizada no questionário

Avaliação divulgada com antecedência

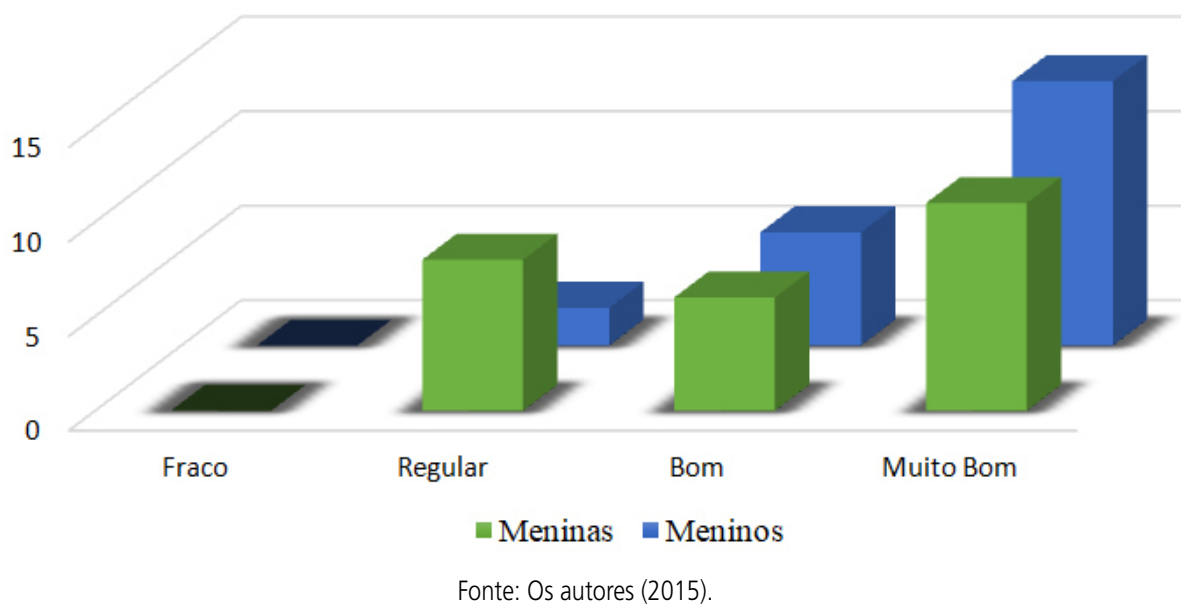


Dessa maneira, avaliar o estudante, dando-lhe avisos antecipados sobre essa atividade, é avaliar sobre uma perspectiva ética e elevar-se com o sentido da construção realizada, da consciência crítica, da autocrítica, do autoconhecimento, investindo na autonomia, autoria, protagonismo e emancipação dos sujeitos, viabilizando-se um caráter educativo e proporcionando ao educando um momento satisfatório para planejar e orientar suas atividades.

No quarto gráfico, gráfico 4, representa-se a ramificação Avaliação, reforçando a aprendizagem. Nesse gráfico é perceptível uma oscilação entre o pensamento masculino do pensamento feminino. Para as meninas, essa ramificação é considerada como Bom, mas os meninos consideram a atitude sobre ela Muito Bom.

Gráfico 4: Resultado da análise sobre a $4^{\mathrm{a}}$ ramificação disponibilizada no questionário Avaliação reforçando a aprendizagem

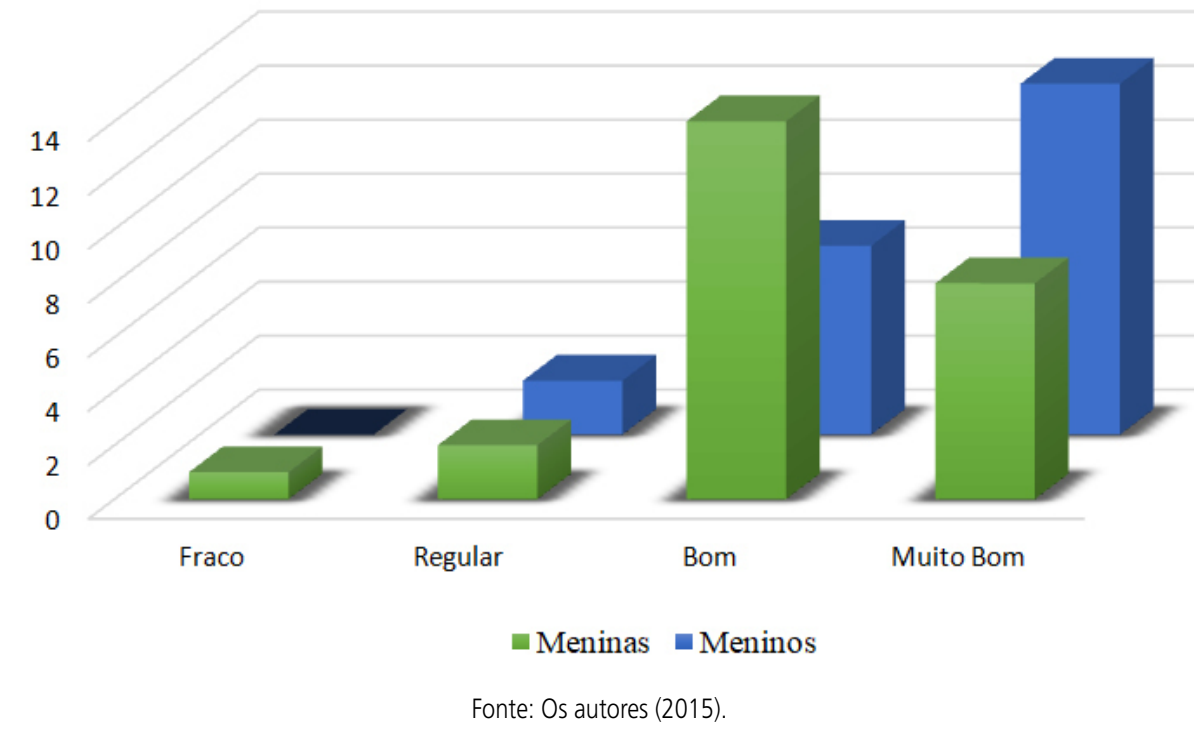

Ao se analisar o gráfico, percebe-se que a oscilação de ideias entre meninos e meninas permanece nas escalas positivas de concordância, pois se para o professor qualquer atividade avaliativa gera ansiedade, pode-se imaginar o que ela representa para os estudantes. Assim, compreende-se que a avaliação deve ser vista e entendida como um mecanismo de formação e emancipaçáo, a qual deve favorecer o desenvolvimento da aprendizagem do estudante, auxiliando-o a 
aprender e constituir-se como cidadáo sociocultural.

Nessa vertente, pensa-se que os objetivos traçados na sala de aula pelo professor devem, no momento avaliativo, ser questionados e instigados de forma mais abrangente pelo estudante, pois o professor deve atuar como estimulador do pensamento, já que cabe ao educando construir o seu saber; o mesmo vale para o próprio conhecimento, sendo o parâmetro de si mesmo no que diz respeito ao seu desenvolvimento. Por isso, Moreto (2008) enfatiza que o estudante

[...] ele é o construtor do próprio conhecimento. Essa construção se dá com a mediação do professor, numa ação do aluno que estabelece a relaçấo entre suas concepçóes prévias e o objeto do conhecimento proposto pela escola. Assim, fica claro que a construção do conhecimento é um processo interior do sujeito da aprendizagem, estimulado por condiçốes exteriores criadas pelo professor. Por isso dizemos que cabe a este o papel de catalisador do processo de aprendizagem. (p. 87).

Nesse desenho, as atividades docentes, sobre uma investigação contínua acerca dos processos de construção da aprendizagem, demandam registros metodológico, os quais se constituem de forma significativa, pois sinalizam as possibilidades de intervençóes necessárias ao avanço e à construção do conhecimento. Portanto, é evidente que esses registros se constituem na socialização e decodificação de informaçôes em prol da construção de saberes necessários à aprendizagem.

Práticas e decisóes democráticas se legitimam na participação e se qualificam na reunião de iguais e diferentes, na organização de coletivos, na intermediação e superação de conflitos e na convivência com o contraditório (SEDUC, 2011, p. 20).

No último gráfico, gráfico 5, percebe-se que os meninos afirmam que as técnicas utilizadas nas avaliaçóes foram o suficiente para lograr, na escala de concordância, uma consideração Muito Bom. Entretanto, as meninas se dividem entre as concordâncias, oscilando consideravelmente entre Regular, Bom e Muito Bom. 
Gráfico 5: Resultado da análise sobre a $5^{\mathrm{a}}$ ramificação disponibilizada no questionário

\section{Avaliação com múltiplos métodos e técnicas}

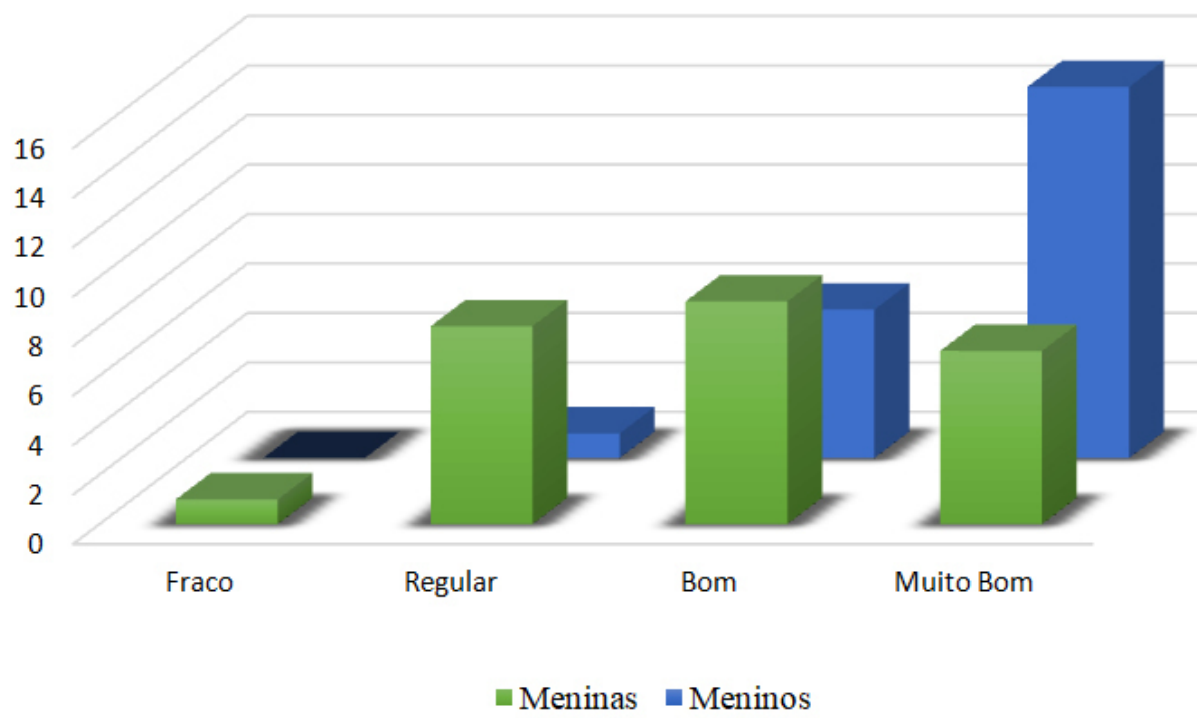

Fonte: Os autores (2015)

Apesar da grande divergência apresentada na escala de concordância pelas meninas, é necessário destacar que os processos avaliativos, como quaisquer outros processos educacionais que interfiram diretamente nos processos de ensino e de aprendizagem, merecem estar pautados em diversas formas e maneiras, isso é, o professor precisa desenvolver práticas pedagógicas e materiais didáticos diversos para, de certa forma, fazer com que o educando se sinta à vontade para o seu desenvolvimento. Nessa teia, os aparatos teóricos da Seduc (2011) explicitam que "é necessário que os responsáveis pelo desenvolvimento do trabalho pedagógico na escola assumam o compromisso de incorporar novas práticas avaliativas, na medida em que se propóem a uma mudança de paradigma." (p. 20).

Assim, compreende-se que a avaliação tem um sentido amplo e significativo, devendo ser feita de formas diversas, com instrumentos variados, sendo o mais comum, e apenas um dos métodos, a prova escrita. Contudo, destaca-se que "[...] se tivermos que elaborar provas, que sejam bem feitas, atingindo seu real objetivo" (MORETO, 2008, p. 87), ou seja, as questóes descritivas ou objetivas inseridas em uma avaliação devem ser bem elaboradas, fazendo com que o 
estudante possa aprender com ela. Assim, percebe-se a necessidade de desenvolver procedimentos que demonstrem aos estudantes as relaçóes existentes e permitam que eles adquiram atitudes pertinentes com o desenvolvimento pleno da cidadania (MORALES, 2003, p. 115)

Considerando a parte virtual para a coleta de dados, como já supracitado, fez-se uma questão para abarcar interaçóes entre professores e estudantes nas redes sociais. A imagem 1, na sequência, apresenta a questáo disponibilizada na rede.

Ilustração 1: Questão disponibilizada na rede para a emersão do diálogo

\section{ATIVIDADE RECENTE}

\section{Estudantes, professores... vamos discutir sobre a questão} de avaliação no politécnico. $O$ que vocês pensam a respeito?

\section{Curtir - Comentar}

\section{B \\ Visualizar comentários anteriores}

Visualizado por 47

3 de 133

Fonte: Os autores (2015).

Averiguando-se a questão, pode-se perceber que houve um número consideravelmente bom de interações, totalizando entre professores e estudantes 133 comentários. Uma análise quantitativa foi realizada sobre as interaçóes e foi possível, com o auxílio do software Ucinet, construir o garfo da sequência, o qual se considera como uma técnica das representaçôes gráficas para visualizar uma rede. Simplificadamente, um grafo é constituído de nós (n) e de ligaçóes (l) que conectam os nós ${ }^{6}$.

6 Os atores são o primeiro elemento da rede social, representados pelos nós (ou nodos). Trata-se das pessoas envolvidas na rede que se analisa. Como partes do sistema, os atores atuam de forma a moldar as estruturas sociais, por meio da interação e da constituição de laços sociais (RECUERO, 2009, p. 26). 


\section{Grafo 1: Grafo realizado a partir das interações da rede}

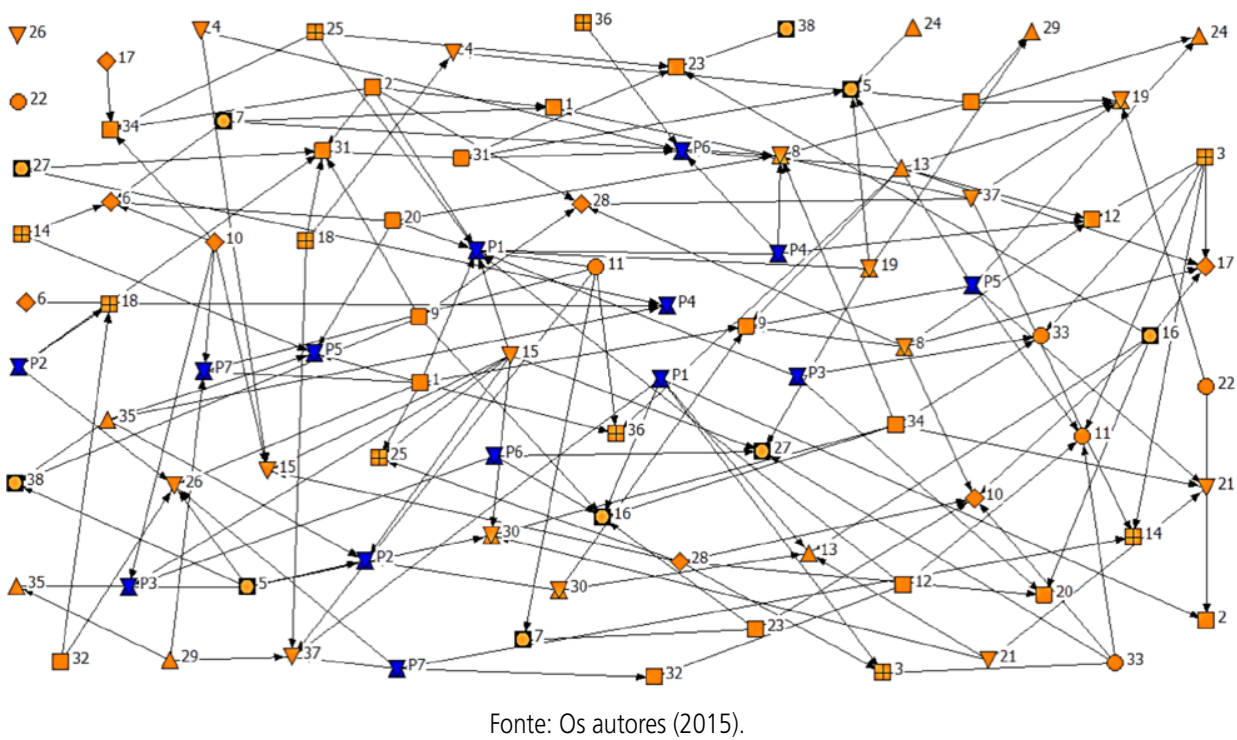

Portanto, entende-se que as redes sociais são úteis e compreensíveis para serem objetos de coleta de dados, pois o software de Teoria de Grafo que foi utilizado conseguiu, a partir de um processamento, enfatizar de maneira simples e interativa o comportamento dos sujeitos. Ao analisar o grafo, percebe-se que o número dos sujeitos está dobrado, isso porque se consideram duas vias. A primeira quando eram indicados pelos sujeitos, recebendo comentários, críticas ou sugestóes, e a segunda quando esses apontavam algo para outra pessoa, podendo ser percebida com a indicação da seta. Destaca-se que em cor azul são os professores e em cor laranja, indiferente das figuras, os estudantes.

Uma análise minuciosa sobre o grafo apresenta a relação entre os sujeitos, a qual é dada a partir do número de vértices ou nós de um grafo. O grau de um vértice diz respeito ao número de conexóes que um vértice possui, o que significa que quanto mais arestas um vértice possuir, maior é seu grau e maior é a sua significância no grafo. Assim, no gafo antes apresentado podese destacar o P1, o qual interage significativamente com muitos estudantes. Já o P4, além de interagir com os estudantes, interage, também, com os professores. Entretanto, destaca-se que o estudante 26 apenas responde à questão na rede e, apesar de receber críticas, sugestóes e/ou questionamento dos demais colegas, não realiza nenhum outro comentário, justificando seu isolamento no grafo em relação à indicação de setas. 
Nessa perspectiva, ao analisar o grafo 1, pode-se perceber que apresenta uma centralidade. Essa centralidade, considerada como a pessoa de maior impacto no grupo, pois apresenta um maior número de relaçôes/laços com os sujeitos, o que favorece o desenvolvimento do diálogo e a proliferação das diferentes concepçóes, é o P1; no grafo, é perceptível que ele se relaciona diretamente com cinco sujeitos, mas é questionado e/ou indagado por 10 integrantes diferentes. Nesse sentido, P1 traz consigo a intuiçáo de poder, uma vez que "quanto mais central é um indivíduo, mais bem posicionado ele está em relação às trocas e à comunicação, o que aumenta seu poder na rede." (BEDIN; DEL PINO, 2016, p. 14).

Em um viés mais analítico, calculou-se a densidade do grafo. A densidade é uma propriedade que está relacionada diretamente com a quantidade de laços existentes. Em especial, Granovetter (1992) explica que quanto maior for o número de conexóes entre os sujeitos da rede, mais informaçôes são proliferadas e socializadas, o que, de fato, favorece a aquisição e a construção significativa de ideias sobre os impactos do caráter emancipatório da avaliação entre os sujeitos.

Por meio da extensão da rede, a qual se encontra altamente interconectada, pode-se calcular a densidade (BRASS; BUTTERFIELD; SKAGGS, 1998). Essa ação matemática deriva-se de cálculos realizados com a fórmula da imagem 2. Portanto, a densidade (D) de uma rede é definida como a relação entre o número de arestas (E) para o número de arestas possíveis, dada pelo coeficiente binomial (N/2).

Imagem 2 - Fórmula utilizada para cálculo da densidade

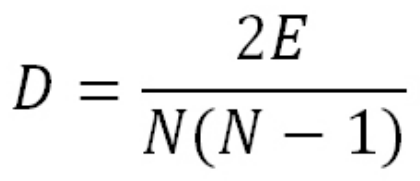

Fonte: Acervo dos autores, 2015

Com a análise do grafo 1 , assim como na imagem 1, pode-se constatar um número expressivo de 133 relaçôes. Contudo, pelo número de integrantes da rede e, por meio da fórmula presente na imagem 2 , constata-se que a densidade do grafo deveria ser superior àquele presente, calculando-se 1.247 relaçóes. Todavia, essa baixa densidade é justificada por ser expressa à luz das relaçóes entre os sujeitos. Ou seja, apesar de o P1, sujeito pontuado como centralidade, ser questionado por 10 integrantes do grupo, ele apenas se relaciona 
diretamente com cinco, o que, consequentemente, baixa a densidade do grafo; isso ocorre com muitos outros integrantes, pois a funçáo de se relacionar com um sujeito e dele não receber respaldo é algo que demonstra a baixa relação e, automaticamente, a baixa densidade.

Contudo, é sagaz mencionar que essa baixa densidade não afeta, de forma alguma, o real objetivo da atividade e/ou a relação entre os sujeitos à luz da troca de concepçôes em relação à avaliação de caráter emancipatório, uma vez que o objetivo da atividade foi proporcionar um diálogo entre os sujeitos e, desse diálogo, extrair as palavras que mais se repetiam em relação à avaliação. O indicado, segundo Santos (2013), é usar um grafo com baixa densidade, pois, a olho nu, é possível avaliar a relação e a conexão entre os sujeitos.

Portanto, de acordo com Alves (2010, p. 159), “[...] a aprendizagem em rede enfatiza processos colaborativos na medida em que permite ao grupo vivenciar distintos papéis e momentos, nos quais a comunicação é descentralizada, permitindo que diferentes vozes sejam escutadas." De outra forma, percebese na relação que se estabelece na rede, entre professores e estudantes, e, em especial nas raízes da visão construtivista-sociointeracionista, que os sujeitos interagem para dialogar em prol de uma temática extremamente importante, pois, de certa forma, a avaliação é um processo que se configura em construção de conhecimento, sendo esse interferido a todo o momento. $\mathrm{O}$ conhecimento não é visto como uma descrição do mundo, mas sim como uma representação que o sujeito faz do mundo que o rodeia, em razáo de suas experiências; logo, se diz que "todo conhecimento é uma construção individual mediada pelo social." (MORETO, 2008)

Do mesmo modo, o modelo construtivista propóe uma nova relação entre professor, estudante e conhecimento, partindo do princípio de que o estudante não é acumulador e repetidor de informaçóes recebidas. Assim, percebe-se que não só os alunos, mas também os professores envolvidos na discussão na rede podem, a partir dela, refletir sobre sua própria interferência e evolução na construção do conhecimento via atividades avaliativas, pois a reflexão sobre os instrumentos preparados pelo professor pode ser um caminho para a conscientização e a democratização da prática avaliativa.

Sobre a questão de conhecimento construído a partir de processos avaliativos, fez-se uma interpretação das escrituras dos sujeitos para entender, em palavras-chave, a concepção deles sobre o processo avaliativo no Ensino Médio Politécnico. Após as análises, as palavras com maior destaque foram submetidas ao software Wordle, o qual apresenta uma nuvem de palavras de tamanhos diferentes, sendo as de maior tamanho as mais citadas/repetidas. Observe a imagem seguinte. 
Ilustração 2: Relação das palavras-chave extraída da rede

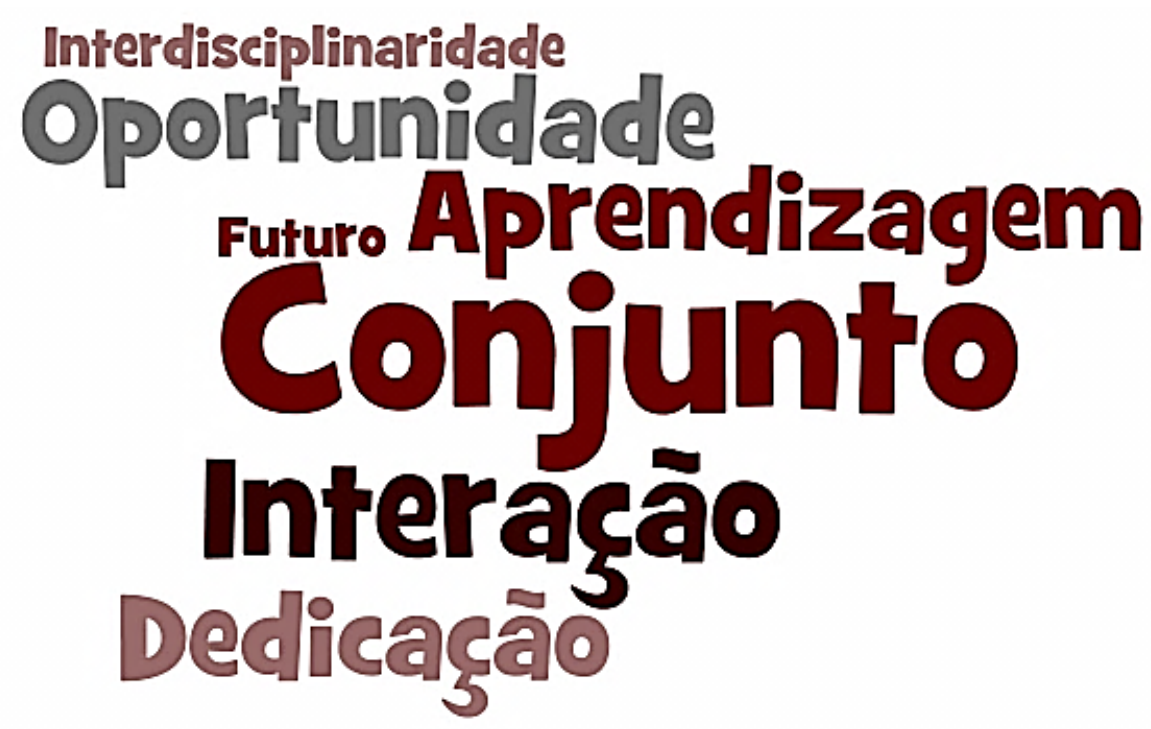

Fonte: Os autores (2015).

Avaliando a imagem apresentada (Ilustração 2), pode-se entender que a análise a partir das escrituras dos professores e estudantes apresenta, dentre várias palavras, conjunto como a palavra de maior tamanho, isso porque os estudantes, ao se referirem às atividades avaliativas no Ensino Médio Politécnico, destacam ser produtivas na questáo de avaliar o conjunto do estudante, não apenas seus conhecimentos teóricos ou práticos.

Dentre outras palavras, citam a questão da necessidade de ampla dedicação e oportunidade de reaprender, já que as atividades aplicadas fomentam a questão emancipatória, considerando as questóes de cunho interdisciplinar, uma vez que as avaliaçóes passaram a ser por área de conhecimento. Do mesmo modo, refletem que esse modelo de ensino trouxe, nas questóes avaliativas, uma maior interaçáo entre os professores e os estudantes, favorecendo a construção do conhecimento nos processos de ensino e de aprendizagem.

Assim, compreende-se a estudante 28, quando afirma que essa metodologia é importante por "[...] avaliar o desempenho e participação do aluno no decorrer das aulas e não somente nas provas." Nesse mesmo viés, a estudante 19 reflete que "[...] é interessante essa forma de avaliação, onde o aluno é avaliado por um conjunto de requisitos, pois, assim, acontece um apanhado geral de cada um, levando em consideração tudo o que este faz em sala de aula e não apenas pelo seu conhecimento teórico.” Nessa mesma teia, a professora 
P3 engrandece os comentários, afirmando que esse modelo de ensino, por meio das práticas avaliativas, "[...] possibilita ver o aluno de uma forma mais ampla, holística, e isso valoriza e muito todas as potencialidades que um ser humano possui."

Assim, entende-se os pressupostos do documento-base da Seduc, pois o processo avaliativo, quando desempenhado de forma emancipatória, mostra-se contínuo, participativo, diagnóstico e investigativo, intensamente ligado à concepção de conhecimento e currículo, proporcionando o tempo adequado para a aprendizagem de cada estudante e no seu coletivo. Nessa perspectiva, tem-se que a finalidade das atividades de cunho emancipatório constitua a açáo de diagnosticar avanços e entraves nos processos de ensino e aprendizagem para, posteriormente, os sujeitos serem capazes de intervir, atuar, problematizar e redefinir rumos a serem percorridos.

Por fim, destaca-se que quanto aos processos avaliativos, o conceito de avaliação emancipatória (SAUL, 1998), adotado no Ensino Médio Politécnico, funciona como instrumento que potencializa a construção da aprendizagem discente, compreendendo o dizer e o fazer como elementos indissociáveis, uma vez que reconhece a importância do aluno no processo de aprendizagem, não como um reprodutor, mas como o próprio centro da produção de conhecimento. Assim, ensino e aprendizagem são processos conectados, indissociáveis, frutos da relação professor-aluno-conhecimento.

\section{Conclusão}

Em virtude dos dados apresentados neste trabalho, pode-se perceber que a avaliação escolar que se pratica na escola investigada, por meio das concepçóes docentes e discentes, é uma constante prática de ação-reflexão do professor e um importante instrumento de qualificaçáo do saber dos estudantes, pois os auxilia na tomada de decisóes e planejamento de estratégias. Contudo, ressalva-se que os professores, responsáveis pelas atividades avaliativas, buscam produzir instrumentos eficientes, os quais instigam ao máximo as competências múltiplas dos estudantes. Além de divulgar as avaliações com antecedência, os professores tratam as atividades desse cunho como interfaces para a qualificação dos processos de ensino e aprendizagem, uma vez que esses instrumentos proporcionam a concordância aos estudantes e seu futuro.

Nessa perspectiva, entende-se que as atividades desenvolvidas na escola asseguram a aprendizagem para os estudantes de forma colaborativa e emancipatória, pois a avaliação emancipatória contribui para a cooperação 
a partir de açóes coletivas, permeadas pelo reconhecimento intrínseco da importância da ação do outro sobre a própria construção do saber. Assim, professor e estudante tomam consciência dos aspectos necessários para desenvolver competências e habilidades em prol de manter o processo de forma qualificada, pois a consciência do próprio processo de aperfeiçoamento e da relação professor-aluno irá possibilitar aos sujeitos crescimento pessoal e social.

Da mesma forma, destaca-se que promover a participação do estudante no processo avaliativo é considerar a democracia para a potencialização do ensino, uma vez que, conforme cita Freire (1996), só aprendemos a participar na medida em que participamos. Portanto, é imprescindível garantir aos professores uma boa formação inicial e continuada nas raízes da avaliação, pois aqueles que usam inadequadamente a avaliação, acredita-se, só o fazem porque não estão devidamente preparados.

Nesse aspecto, destaca-se que as práticas avaliativas envolvem, mesmos que superficialmente, aspectos afetivos, não se restringindo apenas a aspectos cognitivos. Assim, acredita-se que o processo avaliativo, para qualificar os processos de ensino e de aprendizagem, deve ser planejado e desenvolvido para intensificar o processo de aquisição do conhecimento pelo estudante, pois, segundo Leite e Tassoni (2002, p. 17), "[...] pode-se afirmar, sem exageros, que a qualidade da mediação pedagógica, em muitos casos, determina toda a história futura da relação entre o aluno e um determinado conteúdo ou prática desenvolvida na escola."

Finalizando, é pertinente sugerir que as escolas e, principalmente, os professores, considerem a participação e a valorização dos estudantes no processo avaliativo, analisando os exercícios feitos em casa e em sala de aula, garantindo múltiplas formas de avaliar o educando, por exemplo, em trabalhos de pesquisa coletivos ou individuais, mesas-redondas, interpretaçáo de textos e realização de atividades de sistematização, além de organização do caderno, conduta e participação por meio do interesse e dedicação. Assim, entende-se que os métodos avaliativos podem desencadear açóes e processos emancipatórios e formativos, pois as ações supracitadas normalmente não são plausíveis de avaliação em uma prova tradicional, sendo respeitável e necessário o emprego de vários instrumentos, técnicas e métodos para avaliar o estudante em todas as suas vertentes. 


\section{Referências}

ÁLVAREZ MÉNDEZ, J. M. Avaliar para conhecer: examinar para excluir. Porto Alegre: Artmed, 2002.

ALVES, Lynn. Aprendizagem em rede e formação docente: trilhando caminhos para a autonomia, a colaboração e a cooperação. In: VEIGA, I.; D’ÁVILA, C. (Org.). Profissáo docente: novos sentidos, novas perspectivas. 2. ed. Campinas: Papirus, 2010.

BEDIN, E.; DEL PINO, J. C. A emersáo da interdisciplinaridade no ensino médio politécnico: relaçóes que se estabelecem de forma colaborativa na qualificaçáo dos processos de ensino e aprendizagem à luz das tecnologias de informaçáo e comunicaçáo. Tese (Doutorado em Educaçáo) - Universidade Federal do Rio Grande do Sul. Instituto de Ciências Básicas da Saúde. Programa de Pós-Graduação em Educação em Ciências: Química da Vida e Saúde, Porto Alegre, 2015.

BEDIN, E; DEL PINO, J. C. A importância das redes sociais no ensino médio politécnico: aprendizagem colaborativa. \# Tear: Rev. de Educação Ciência e Tecnologia, v. 5, n. 1, 2016.

BORGATTI, S. P.; EVERETT, M. G.; FREEMAN, L. C. UCINET 6 for Windows: Software for social network analysis. Harvard: Analytic Technologies, 2002.

BRASS, Daniel; BUTTERFIELD, Kenneth; SKAGGS, Bruce. Relationships and unethical behavior: a social network perspective. Academy of Management Review, v. 23, p. 14-31, 1998.

CALDEIRA, A. M. S. Avaliação e processo de ensino-aprendizagem. Presença Pedagógica, Belo Horizonte, v. 3, p. 53-61, set./out. 2000.

FREIRE, P. Pedagogia da autonomia: saberes necessários a prática educativa. São Paulo: Paz e Terra, 1996.

GRANOVETTER, M. Problems of explanation in economic sociology. In: NOHRIA, N.; ECCLES, R. (Org.). Networks and organizations: structure, form, and action. Boston, Mas-sachussetts: Harvard Business School Press, 1992.

HOFFMANN, J. M. L. Avaliaçáo mediadora: uma prática em construção da pré-escola à universidade. 20. ed. Porto Alegre: Mediação, 2003.

LEITE, S. A. S.; TASSONI, E. C. M. A afetividade em sala de aula: as condiçóes de ensino e a mediação do professor. In: Azzi, R. G.; Sadalla, A. M. F. A. (Org.). 
Psicologia e formaçáo docente: desafios e conversas. São Paulo: Casa do Psicólogo, 2002.

LUCKESI, C. C. Avaliaçáo educacional escolar: para além do autoritarismo. Tecnologia Educacional, Rio de Janeiro, 1984.

LUCKESI, C. C. Avaliação da aprendizagem: componente do ato pedagógico. São Paulo: Cortez, 2011.

LUCKESI, C. C. Avaliaçáo da aprendizagem na escola: reelaborando conceitos e recriando a prática. 7. ed. Salvador: Malabares Comunicação e Eventos, 2003. MORALES, P. Avaliaçáo escolar: o que é, como se faz. Rio de Janeiro: Loyola, 2003. MORETO, V. P. Prova: um momento privilegiado de estudo, náo um acerto de contas. 8. ed. Rio de Janeiro: Lamparina, 2008.

RECUERO. R. Redes Sociais na Internet. Porto Alegre. Editora Meridional, 2009.

SANTOS, L. T. Otimizaçáo de fluxos em grafos. Trabalho de conclusão de curso apresentado para obtenção do grau de bacharel em ciência da computação da Universidade Federal do Paraná, UFPR, 2013.

SAUL, A. M. Avaliaçáo emancipatória: desafios à teoria e à prática de avaliação e reformulação de currículo. 3.ed. São Paulo: Cortez,1995.

SAUL, A. M. Avaliação Emancipatória. São Paulo: Cortez, 1998.

SAUL, A. M. Na contramão da lógica do controle em contextos de avaliação: por uma educação democrática e emancipatória. Educ. Pesqui., São Paulo, v. 41, n. especial, p. 1299-1311, dez. 2015. Disponível em: <http://www.scielo.br/pdf/ep/ v41nspe/1517-9702-ep-41-spe-1299.pdf>. Acesso em: 04 out. 2017.

SEDUCRS. (2011-2014). Proposta Pedagógica Para o Ensino Médio Politécnico e Educação Profissional Integrada ao Ensino Médio, 2011. Disponível em: <http://www.educacao.rs.gov.br/dados/ens_med_proposta.pdf>. Acesso em: 27 jan. 2015.

YIN, R. Case Study Research: Design and Methods. Thousand Oaks, CA: SAGE Publications, 1994. 